\title{
O ensaio como vocação: intelectuais latino-americanos e experiência intelectual (semi)periférica no século XIX
}

\author{
Essay as a vocation: Latin American intelletuals and (semi)peripheral intellectual \\ experience in the 19th century
}

Maro Lara Martins

Doutor em Sociologia pelo Instituto de Estudos Sociais e Políticos da Universidade do Estado do Rio de Janeiro (Iesp-Uerj)

Professor Adjunto do Departamento de Ciências Sociais da UFES marolara@gmail.com

\begin{abstract}
Resumo: Este texto aborda a transfiguração do ensaio em terras americanas, apontando as características desta forma de apresentação das ideias, relacionando o conteúdo ao contexto. Em outras palavras, o ensaio latinoamericano se apropriou de conceitos originários de sistemas filosóficos e científicos os mais diversos, e, libertando-os do peso desta origem, da pureza e transcendência que esta transposição impunha, os (re)significou a partir de sua inserção em uma forma discursiva nova, em uma experiência intelectual específica e interina. Deste modo, fugiu aos padrões frios da descrição analítica e da erudição ao se colocar no mundo público, como interpretação de um novo mundo, com seus habitantes e território. Desenhando assim, uma peculiar episteme (semi)periférica cuja centralidade se ancoraria na inventividade e no pragmatismo, postos na confluência da imposição pessoal e da palavra pública.
\end{abstract}

Palavras-chave: América Latina, Pensamento Político e Social, Ensaio.

\begin{abstract}
This paper addresses the transfiguration of the essay on Latin American, pointing out the features of this form of presentation of ideas, relating the content and context . In other words, the Latin American essays appropriated concepts originate in philosophical and scientific systems, and free them from the burden of this origin, purity and transcendence that this transposition was necessary, the (re)meant from their inclusion in a new discursive form, in a specific and interim intellectual experience. Thus, fled the cold standards of analytical description and learning to put yourself in the public world, building their state, defining as interpretation of a new world, with population and territory. Drawing thus a peculiar peripheral episteme whose centrality is anchored in inventiveness and pragmatism, placed at the confluence of personal taxation and public word.
\end{abstract}

Keywords: Latin America, Latin American Political e Social Theory. 
Este texto é composto por dois movimentos interdependentes. O primeiro é a busca por uma definição geral do estilo de escrita ensaio. O segundo diz respeito à formas de apropriação e reinserção desse estilo em um contexto diverso do europeu. $\mathrm{Na}$ primeira parte, se realiza uma breve exposição das principais características do ensaio enquanto forma de escrita e de exposição das ideias. Apesar da crítica literária ter se dedicado e estabelecido certos parâmetros, se recorreu a algumas proposições de Georg Lukács e Theodor Adorno sobre o ensaio para se estabelecer algumas referências para a discussão do alcance do ensaio como forma adequada de conhecimento da realidade. Ademais, se indicou mesmo que superficialmente, as trajetórias do ensaio como tradições nacionais de interpretação que paulatinamente ganharam expressão através de certos temas e debates. Nas origens, se o texto de Montaigne se tornou fundamental para o estabelecimento deste suporte de escrita, o ensaio conheceu diversas trajetórias na Europa central, sendo apropriado pela filosofia alemã, pelo debate cultural inglês e pela crítica francesa. Seguindo este raciocínio, se considera que os elementos distintivos do ensaio, enquanto proposição de uma teoria geral como a concebida por Lukács e Adorno, não são suficientes para a exaustão analítica sobre os modos pelos quais estão disponíveis certos estilos aos autores e os usos pelos quais se constrói a argumentação proposta por cada autor.

No segundo tópico do texto, se estabelece uma reflexão sobre o ensaio latinoamericano, sua vocação para a participação na vida pública da região e a experiência intelectual latino-americana. Inicialmente, se localiza duas tradições de interpretação sobre ensaio no território, uma que se utiliza de uma metáfora da América enquanto ensaio civilizatório e outra que localizou o ensaio e a vocação ensaística latinoamericana conectada aos movimentos de autonomia política-institucional do continente. Em seguida, se encaminha a ponderação de que a proliferação do ensaio nesta região periférica ajudou a configurar um pensamento que tenderia a expressar-se através de uma relação com sua sociedade e seu território, a partir de sua posição e de sua experiência intelectual. Nestes termos, se indica a persistência de práticas cognitivas do mundo em territórios fora do eixo europeu e sua imbricação com a forma como as ideias são apresentadas. Em seguida, se relaciona essa forma periférica de apresentação das ideias com a característica típica desses territórios, na confluência para a inventividade, em seu aspecto construtivo, o inacabamento e a concepção desses territórios como um campo de experimentação da modernidade. Assim, a América Latina, na visão de seus intérpretes, emergiria como um espaço de projetos. 


\section{Os contornos da escrita: as formas do ensaio}

Não é intenção deste texto propor uma revisão da teoria do ensaio a partir da ótica da teoria literária. Entretanto, torna-se fundamental uma caracterização geral do ensaio como forma de escrita, para posteriormente se estabelecer alguns parâmetros sobre os quais repousam o objeto de estudo dessa tese. Assim, o caminho proposto é o de ir além da relação estética e da experiência formal contidos nesse objeto de estudo.

As posições de Georg Lukács e Theodor Adorno tornaram-se referência para a discussão do alcance do ensaio como forma adequada de conhecimento da realidade. Para Lukács (2009), o ensaio como forma partiria da renúncia ao direito absoluto do método e da ilusão de poder resolver pela forma o sistema de contradições e tensões da vida. O ensaio não obedeceria a regras da ciência, tampouco da filosofia, para as quais a ordem das coisas seria o mesmo que a ordem das ideias. Pelo contrário, o ensaio, partindo da consciência da não identificação seria radical em seu não radicalismo, na abstenção de reduzir o todo a um princípio, na acentuação do parcial frente ao total em seu caráter fragmentário. O ensaio, nesta concepção, seria a forma de decomposição da unidade e da reunificação hipotética das partes, no sentido que daria movimento ao imaginar a dinâmica da vida, reunindo estruturas provisórias do que estaria dividido, e distingui-lo do todo que se apresentaria como unidade.

Esse movimento, instante fugaz, deveria propiciar ao ensaio uma distinção central na filosofia de Lukács: a oposição entre vida cotidiana e vida autêntica. A existência autêntica seria a única capaz de permitir ao homem deixar de conceber a morte como um limite que apaga sua existência e ilude seu sentido. Nestes termos, a busca por Lukács da forma para dotar a vida de sentido encontraria no ensaio uma expressão que dotaria de sentido a vida autêntica como gesto reflexivo. De modo que nos seus escritos sobre a forma e alma, o que pareceria ser dois discursos separados, o fictício e o teórico, ${ }^{1}$ constituem a mesma resposta para a tragicidade da vida.

No fundo, para Lukács, o ensaio expressaria uma síntese da vida, que buscasse a dinâmica efetiva dos elementos dela. Entretanto, a impossibilidade de se dar uma forma à vida, de resolver sua antítese na dimensão afirmativa de uma cultura, obrigaria o ensaio a se autointerpretar como representação provisória e como ponto de partida de outras formas, de outras possibilidades. Daí seu caráter errante entre a forma e sua

\footnotetext{
${ }^{1}$ Foi historiador da arte, de nacionalidade húngara e amigo de Georgy Lukács.
} 
superação irônica, entre a forma como destino e a aforia de uma forma como totalidade independente. Dito de outro modo, essa irrupção irônica que se alimentaria da surpresa de se observar a suspensão da ideia de absoluto, através da irrupção de coisas fragmentárias da vida, assinalaria que através do jogo e das variações e configurações da vida se renunciaria as formas de evidência do real, e impõem ao ensaio um procedimento abstrato, que determinaria tanto sua estratégia discursiva como a forma de conhecimento que seria própria.

A diferenciação do ensaio de outras formas como a poesia, seria que a poesia receberia o destino em seu perfil, em sua forma, enquanto no ensaio, a forma se faria destino, ou ao mesmo o princípio do destino, uma vez que decidiria a resolução particular dos possíveis. O ensaio necessitaria da forma enquanto vivência, para realizar-se na consciência da vida através do desacordo entre a vida e suas instâncias de representação e explicação. Estas postulações de Lukács seriam retomadas por Adorno que encaminharia a discussão sobre o modo de escritura do ensaio a outro ponto.

Para Adorno, a forma ensaística é pensada como o estilo ou a maneira de se fazer filosofia, que de uma maneira geral, não só eximiria o texto de cair na armadilha das tradições acadêmicas e científicas, portadoras de uma tradição de pensamento conservador, mas, sobretudo, permitiria uma maior precisão filosófica do que outros suportes literários. Ciência e filosofia se valeriam de uma interpretação conceitual da realidade, de um amálgama entre a ordem das coisas e a ordem dos conceitos.

Para percorrer esse denso traçado que a revolta do estilo sobrepujaria, implicaria compreender as tensões entre história e filosofia, ideologia e pensamento. Adorno buscou as matrizes de onde o problema teria emergido: a separação incondicional entre ciência e arte e a consequente fragmentação da unidade do saber, em saberes científico e artístico.

A entidade constitutiva desta forma de apreensão, somente seria definível mediante a habilitação de uma operação reflexiva que oscilaria entre a sensação e a impressão, a opinião e o juízo lógico. É fundamentalmente o discurso sintético da pluralidade discursiva unificada pela consideração crítica do indivíduo. Por outro lado, o ensaio tenderia a possibilitar o tratamento de tudo o que lhe fosse suscetível de ser tomado como objeto conveniente ou interessante para a reflexão. A liberdade do ensaio adviria tanto de sua organização discursiva e textual como de seu horizonte de eleição temática. 
Essa insinuação de não acabamento do ensaio seria o movimento que perpetuaria o seu vôo ao infinito. Os objetos, as premissas, os conceitos e os fins, não poderiam ser omitidos, mas também não poderiam ser sistematicamente determinados por uma linguagem tradicional.

A postura crítica do ensaio, a sua cor própria, estaria presente em seu conteúdo e sua forma. Primeiro, transpareceria em seu conteúdo na medida em que um dos temas examinados seria a própria forma de apresentação da filosofia e dos seus conceitos. Segundo, o próprio ensaio seria, em sua forma, uma resposta possível ao problema elaborado no conteúdo do texto. O que resguardaria o ensaio de fracassar como a tentativa de meta-arte, por exemplo.

O ensaio trabalharia em cima de conceitos, "ele necessariamente se aproxima da teoria, em razão dos conceitos que nele aparecem trazendo de fora não só seus significados, mas também seus referenciais teóricos" (ADORNO, 2003: 37). Ele transitaria entre esferas aparentemente desconexas, e estabeleceria à sua vontade as ligações necessárias para usufruir da própria tensão entre forma e conteúdo, entre exposto e exposição, para criar seu próprio caminho. (NOYAMA, 2009) Porém, independente do caminho percorrido, cada um à sua maneira, a forma de apresentação de ideias permaneceria determinada pelos princípios, regras, limites e por todo corpo metodológico do perfil de pensamento que se estabeleceria.

Outra característica fundamental do ensaio, seguindo os passos de Adorno, é que no ensaio se apresentaria o calor do momento, a contemporaneidade explícita do pensamento e do diálogo que o ensaísta necessita efetuar. Assim, "a atualidade do ensaio é anacrônica. A hora lhe é mais desfavorável do que nunca" (ADORNO, 2003: 44).

O ensaio seria um protótipo moderno, uma criação estilística da modernidade, especificamente assinalaria uma perspectiva histórico-intelectual do Ocidente e sua cultura de reflexão especulativa e crítica. ${ }^{2}$ Naturalizado e privilegiado pela cultura da modernidade europeia, o ensaio seria o centro de um espaço que abarcaria o conjunto de textos destinados a resolver as necessidades de expressão e comunicação do pensamento. Assim, o ensaísmo enquanto criação literária, ao reconstruir no interior de sua narrativa um espaço e um tempo próprios, com palavras que em si condensam os sentidos acumulados em seu próprio curso, revelaria os modos peculiares de

\footnotetext{
${ }^{2}$ Sobre este ponto, conferir: HARO, 1992; OBALDIA, 1995; GOMÉS-MARTINEZ, 1992; EARLE, 1982; WEINBERG, 2002.
} 
interpretação advindos da tradição e da experiência intelectual do seu autor. (ROLAND, 1997: 230).

Dentre os analistas que se aventuraram em traçar a linhagem do ensaio, parece consenso apontar os Ensaios de Michel Montaigne, enquanto textos fundantes deste estilo de escrita. Apontaram que Montaigne construiu a primeira poética do ensaio ao estabelecer quatro características dessa atitude literária: o juízo individual ou subjetivo, o caráter dialógico, a vontade de estilo e a interpretação da realidade. ${ }^{3}$

Os Ensaios resumiriam pensamentos, máximas, conselhos, cujo núcleo temático se encontraria na dispersão das questões que afligiriam seu autor, mediado pela sensação de um indivíduo dramaticamente cindido, desarraigado do mundo, avaliando-o como a si mesmo. (ROLAND, 1997; OBALDIA, 1995) Nestes termos, o ensaio nasceu porque em seu contexto de origem, a Renascença, se deu relevância ao indivíduo dentro do mundo das letras e das artes, aumentando os graus de representação da subjetividade do conhecimento. Esta variação trouxera consigo certa consciência da individualidade, que por sua vez, implicara em uma nova maneira de assumir a inteligibilidade da realidade.

De outro lado, se pensarmos como Costa Lima (1995; 1993), até a época de Montaigne, pontificava a ordem da mimesis, em que a literatura se confundia com a retórica, se enquadrava nas belas letras, não se opondo de forma acentuada a um pensamento que associava a racionalidade à teologia e que muitas vezes se expressava de forma alegórica. Nestes termos, a obra de Montaigne anunciaria a ordem do método e abriria para o sujeito recém descoberto um horizonte vazio, pois ainda não existiria uma lei que substituísse a visão em ruínas da ordem da mimesis. A ordem do método, na ficção, seguindo os passos de Costa Lima, organizaria um controle do imaginário, o processo pelo qual a literatura se autonomizaria enquanto discurso, como um espaço circunscrito e limitado do imaginário individual e social, de modo a minimizar os efeitos que a ficção engendraria nos discursos estabilizados e dominantes da religião, da filosofia ou da ciência.

Nestes termos, o ensaísmo na França, se associaria a ideia de crítica e de passagem da ordem da mimese para a ordem do método, e se associariam "a leituras pessoais de textos literários (um subproduto da teoria literária), ou escritos esparsos (um subproduto da filosofia), ou ainda divagações sobre eventos cotidianos e políticos (caso

\footnotetext{
${ }^{3}$ Cf.: HARO, 1992; OBALDIA, 1995; GOMÉS-MARTINEZ, 1992; EARLE, 1982; WEINBERG, 2002.
} 
em que o ensaio, abastardo, se aproximaria da crônica)" (PINTO, 1998: 76). Desta forma, a tradição francesa do ensaio teria como característica a hesitação entre uma demanda filosófica que seria referencial e um horizonte de representações que tangeria o ficcional.

Se a obra capital de Montaigne fora escrita em 1589, e traduzida para o inglês em 1598, foi em Francis Bacon e David Hume que o ensaio se destacaria na produção intelectual inglesa. $\mathrm{Na}$ Inglaterra, o ensaio floresceria e permaneceria por duas razões: “em primeiro lugar, a fonte do ensaísmo inglês é Bacon, ou seja, um empirista, que de saída, afasta qualquer pretensão sistemática à qual o ensaio se contrapusesse" (PINTO, 1998: 76), em segundo lugar, o ensaio inglês não tem grande proximidade com o ficcional e sua característica marcante é a pluralidade de motivos. Tendo como subsolo uma filosofia empirista e pragmática, o ensaio inglês descreveria o fenômeno da cultura em sua variedade, enquanto no caso francês, existiria a busca de uma identidade à qual fosse redutível toda a experiência humana.

No caso inglês, o ensaio serviu de suporte ao debate sobre a relação entre o homem e a cultura e se difundiria em diversas publicações, mas manteria seu substrato empirista e pragmático. Na França de Montaigne, o estilo teria sido usado para tecer comentários relacionados à crítica literária, estética, filosófica, com propensões de individualidade, e sempre em busca do desvelamento da identidade íntima das coisas. No caso alemão, do qual Adorno se enquadrou, o ensaio se associou a um modo de se fazer filosofia em que se concatenou a sua posição entre a arte e a ciência.

Além de suas características formais enquanto suporte literário, ao se pretender uma análise sobre o ensaio, há que se atentar para as transformações eventuais que ocorrem dentro de certos limites impostos pela tradição nacional. Não há dúvida da pertinência das proposições de Lukács e Adorno acerca do ensaio, buscando uma teoria geral que mobilizaria elementos fundamentais para esse suporte de escrita. Entretanto, por si só, esses elementos constitutivos não são suficientes para o esgotamento analítico que se propõe a abordar os modos pelos quais estão disponíveis certos estilos aos autores e os usos pelos quais se engendra a argumentação proposta por cada autor. $\mathrm{O}$ ensaio na América adquiriu outros contornos, diferentes do contexto europeu. É o tema que se passa a tratar. 


\section{O ensaio como vocação: o ensaísmo latino-americano}

De todo o debate sobre a natureza do ensaio e as tentativas de elaboração de uma teoria geral do ensaio, salta aos olhos a insuficiência de uma possível transposição desse modelo de interpretação aos estilos de escritas realizados fora do eixo europeu sem alguns retoques. Não há dúvida de que a tradição ensaística remontar ao contexto europeu, sofrendo lá, diversas mutações relacionadas à inscrição em tradições nacionais específicas. Associado a isso, o núcleo temático do qual os ensaístas aderiram possui como marca fundamental as variações de tempo e espaço. ${ }^{4}$

Se em Montaigne chamou a atenção para a ausência de uma afeição concentrada, uma causa definida em torno de um tema ou núcleo temático, a não ser o exercício radical da liberdade de viver e escrever e de poder apresentar seu livro como a si mesmo (OBALDIA, 1995) a recepção e recriação desse estilo ao longo do tempo e espaço se alterou consubstancialmente. ${ }^{5}$

O debate sobre as origens do ensaio no continente latino-americano apresenta duas postulações. A primeira apontou o surgimento do ensaio a partir das interpretações realizadas pelos europeus no Novo Mundo, sua necessidade de descrever a paisagem e os seus habitantes. A segunda perspectiva localizou o ensaio dentro do movimento emancipacionista do século XIX, que culminou com as Independências e construções dos Estados nacionais.

Dentro do primeiro ponto de vista, German Arciniegas apontou que a tradição ensaística no continente remontaria ao século XVI, ainda que a palavra ensaio, que nomeará o gênero mais adiante não existisse. O ensaio revelaria uma vontade interpretativa ante o Novo Mundo, ignoto, estranho, distante, que conquistadores e colonizadores intentaram apreender através do poema épico e das crônicas. Arciniegas (1983: 95) afirmou que o ensaio esteve presente "desde os primeiros encontros do branco e do índio, em pleno século XVI". Por metáfora, a América, encarnaria ela mesma, um próprio ensaio. Essa metáfora que definiu a América como um ensaio se explicaria pela eclosão do grande debate que suscitou a aparição de um novo continente na geografia e no imaginário europeu.

\footnotetext{
${ }^{4}$ Neste sentido é preciso historicizar o ensaio. WEINBERG, 2002.

5 "Simplificando, podemos distinguir dois tipos de ensaística. Uma tradicional, de temática variada, que cumpre uma função basicamente intelectual e que floresceu na Europa dos séculos XVI a XVIII e outro, americanizado, que se caracteriza por uma unidade temática centrada na própria identidade e por uma ativa função política, e que conheceu seu auge nos séculos XIX e XX” (HOUVENAGHEL, 2002: 25).
} 
Conquistadores, colonizadores, clérigos e mestiços estariam imersos em especulações religiosas e espirituais que postulariam que a experiência americana, sua natureza e seu homem possuiriam outro significado diferente do europeu, pois a América seria o ensaio civilizatório à aguçar as interpretações.

Seguindo essas ponderações, Arciniegas apontou que Cristóvão Colombo e Américo Vespúcio já continham elementos ensaísticos em suas reflexões. Para ele, Colombo discutiu o problema do paraíso terreal e sua correspondência nas terras que tinha a vista, retirando o debate de textos bíblicos, do catolicismo de sua época e dos geógrafos mais antigos. Américo Vespúcio provocava o debate com os humanistas de Florença acerca da cor dos homens em relação ao clima e a possibilidade de que as terras abaixo da linha do Equador fossem habitadas por seres humanos. Para Arciniegas, teriam sido estes os primeiros ensaios da literatura latino-americana.

Esta intuição de Arciniegas ganhou mais força com Héctor Orjuela (2002), que remontaria as origens do ensaio no Novo Mundo lendo de uma maneira inovadora os discursos dos sacerdotes e conquistadores que possibilitaram a emergência da cultura letrada na América. Para ele, os séculos XVII e XVIII implicaram não somente a aparição do barroco nestas latitudes, mas também a diversificação das manifestações ensaísticas. $\mathrm{O}$ ensaio teria ganhado primazia graças ao estilo cultivado pelos escritores mais destacados da época, como Hernando Domingos Camargo, com sua Invenctiva Apologética, Juan de Cueto y Mena com o Discurso del Amor y la Muerte e Madre Francisca Josefa de la Concepción del Castillo, autora de Afetos Espirituales.

Com a inflexão sobre a natureza, o ambiente e as riquezas materiais e simbólicas do Novo Mundo, estes religiosos e cronistas, cujo interesse e curiosidade científica anunciavam a influência da Ilustração, compartilhavam um traço geracional baseado no assombro e na inovação que em seus horizontes de sentido se fixou a América. Para Orjuela (2002: 83), "os escritores sentiam a necessidade de inventariar os produtos da terra e o habitat dos aborígenes nas diferentes regiões do país e incorporavam a informação da história natural em crônica, tratados e ensaios com temas muito diversos".

No fundo, seriam hermeneutas que começaram a decodificar a fauna, a flora e os matizes do Novo Mundo, para construir mediante o exercício da escrita uma nova identidade a partir da alteridade americana, lugar onde todos os opostos se encontrariam, não para eliminarem-se senão para viverem na diferença em relação ao conhecido continente europeu. Estariam preocupados em direcionar seus escritos ao 
público que se encontrava do outro lado do Atlântico, no esforço de apresentar o Novo Mundo e suas particularidades a partir das diferenças que se encontravam nesses territórios. Ganharia expressões e sentidos diversos essa ambiência. Para uns, a comprovação do paraíso terreal, de um mundo idílico, e para outros, a fúria da natureza e a decadência selvagem. ${ }^{6}$

O importante é que se nota como uma nova aproximação dos textos produzidos nas circunstâncias histórico-culturais advindas da Conquista e da experiência colonial, poderia apoiar a discussão sobre a presença da inflexão ensaística nestas terras antes do surgimento de Montaigne. Entretanto, resulta válida a ponderação de Claudio Maíz (2003) e de Leopoldo Zea (1972) a respeito de que o ensaio é a forma de expressão de conteúdos críticos em períodos específicos. E na América Latina, adquiriu força e constância no século XIX, quando apareceram os "desbravadores da selva e os pais do alfabeto", como os chamou Alfonso Reyes em Passado Inmediato. ${ }^{7}$ Assim, a partir do século XIX, surgiu uma tradição de pensamento sentenciado pelo ensaio para estabelecer um diálogo com o centro assim como para gerar aquilo que Leopoldo Zea chamou de "consciência intelectual da América".

Nesta perspectiva, na América Latina, o ensaio dialogaria em suas origens com as inquietudes próprias dos letrados e polígrafos do século XIX e com os ecos do pensamento ilustrado herdado da Revolução Francesa e do Enciclopedismo, ${ }^{8}$ com o liberalismo nascente, com os próceres da Revolução Americana, com o exemplo da Revolução do Haiti, assim como com a própria tradição ibérica, ${ }^{9}$ definitivos na busca pela expressão ensaística. ${ }^{10}$

\footnotetext{
${ }^{6}$ Sobre as concepções de natureza nas Américas e sua genealogia, ver: GREENBLATT, 1996; PRATT, 1999.

${ }^{7}$ Alfonso Reyes se referia especialmente a Andrés Bello, Domingo Faustino Sarmiento, Eugenio María de Hostos, Justo Sierra, Jose Enrique Rodó e Jose Martí.

${ }^{8}$ Fato que levou a primazia da "Razão política" no século XIX. CARVALHO, 1980 e WERNECK VIANNA, 1997.

${ }^{9}$ Como apontou BARBOZA FILHO, 2000. Os principais elementos que particularizaram a Ibéria em relação ao restante da Europa e que incorporaram-se à tradição americana foram: o territorialismo e sua capacidade de controle sobre espaços cada vez mais amplos, a religiosidade simples e de fronteira que transformou seu movimento territorialista em cruzada, a fixidez da estrutura social, preservada pela capacidade de drenar os conflitos internos para as zonas de expansão, conquistando-as para a reprodução da mesma morfologia social, a centralidade política da Coroa responsável pela ordem jurisdicional e corporativa.

${ }^{10}$ Observando a língua como instrumento da independência, a partir e na literatura latino-americana, Angel Rama colocou em questão a dialética entre originalidade e representatividade, sob um eixo histórico. Rama afirmou que as letras latino-americanas jamais se resignaram com suas origens, tampouco se reconciliaram com o seu passado ibérico, gerando uma tentativa forçosa de originalidade em relação às fontes. Tal empreendimento se refere ao esforço insurgente de construção de linguagens particulares.
} 
Temos assim, que são duas as inquietudes filosóficas dos pioneiros do ensaio na América Latina: a independência e a formação do Estado. Estas questões motivaram uma forte produção ensaística na literatura latino-americana que neste sentido assinala nomes fundamentais como José Joaquín Fernández de Lizardi, Simón Bolívar, Andrés Bello, Juan Montalvo, José Bonifácio, Frei Caneca, Visconde do Uruguai, Tavares Bastos, entre outros. Depois, viriam aqueles que fariam do ensaio o âmbito literário propício para a definição de um continente que oferecia a discussão sobre o passado colonial, a análise dos traços étnicos, a constituição dos Estados nacionais, a crítica aos regimes políticos, a produção intelectual e a ontologia do ser latino-americano como temas dominantes desta nascente tradição ensaística.

$\mathrm{Na}$ linha divisória do passado colonial e da independência frente ao centro político ibérico podemos conferir a vocação do ensaio como construtor dos Estados nacionais latino-americanos em oposição ao contexto anterior, no qual se inseria esta região em um sentido mais amplo de pertencimento ao Império Transatlântico Português e ao Império Transatlântico Espanhol. Uma nova modalidade política se insurgiria contra as antigas valorações de pertencimento, uma nova forma de escrita se insurrecionava contra o que consideravam antigos hábitos de pensamento. ${ }^{11}$ São políticos-intelectuais que entendiam o ensaio como tribuna para inocular mensagens com maior impacto imediato do que poderiam alcançar com a poesia, o romance, obras de ficção ou tratados.

Os primeiros polígrafos e ensaístas são figuras representativas de um processo de interpretação do território para a construção do Estado (BARBOZA FILHO, 2000). Em certa medida, a independência política do espaço não trouxe consigo a criação de um centro que o contextualizara e como os sucessivos intentos de criá-lo partiam, em geral, do artifício sobre a tabula rasa, tais propósitos parecem se converter em projetos individuais, que situados de novo em um centro externo ao próprio território, conceberam que o Novo Mundo começaria por eles. Esses projetos são mediatizados pela reconfiguração do centro político e pelo modo como se construiu cada Estadonação no continente. Por esse viés, é o projeto expansionista do centro político e sua penetração no ideário de cada particularidade histórica que definiu a intensidade e ampliação de cada projeto sobre determinado território.

\footnotetext{
${ }^{11}$ Segundo Angel Rama, essa atitude multitudinal compilou um esforço de "descolonização do espírito" e uma superação do "folclorismo autárquico". Isso denota que a plasticidade contida no ensaio não é mera invenção combinada com vistas a uma dissensão sem substância.
} 
O resultado é que se vai fomentando um permanente estado de expectativa sob a experiência intelectual. Na realidade, esse estado de expectativa era o essencial do antigo conceito de território, quando a fronteira se estendia na linha de encontro ou na confrontação com o outro. Essa permanência da expectativa como contextualização do novo espaço criado, deu lugar a um modo peculiar de se conceber a criação do Estado. ${ }^{12}$

Uma breve reflexão sobre os conceitos-chaves presentes no contexto latinoamericano nos dá um quadro geral das proposições levantadas neste contexto. Se no período colonial o conceito de América possuía um significado geográfico com implicações geopolíticas que indicavam a possessão desta região como parte das monarquias ibéricas, no final do século XVIII e início do XIX, o termo se converteu em bandeira de mobilização política, "acabando inclusive por integrar o nome de algumas comunidades políticas recentemente liberadas do vulgo colonial" (FEREZ JUNIOR, 2009: 53). Associado a isso, o termo americano passara a ser uma identidade política que diferenciava os europeus dos nascidos na região. "Este deslocamento semântico redundou inclusive na perda de importância relativa do termo criollo como identidade política principal. Esse exemplo histórico nos leva a uma questão teórica importante: a capacidade das instituições para mudar a cultura política, redefinido seus conceitos básicos" (FEREZ JUNIOR, 2009: 60).

Redefinição observada no conceito de povo, como instância legitimadora do processo de fundação política, que de vocábulo marginal, se tornou referência constante no pensamento latino-americano. Neste sentido, “é inegável que o movimento de semantização do vocábulo povo - levado para o centro do discurso político - esteve indissociavelmente ligado a necessidade de dotar de legitimidade a ruptura com o Antigo Regime e com sua respectiva concepção de soberania” (WASSERMAN, 2009: 118). O conceito de cidadão, vinculado necessariamente a uma comunidade, também se alterou no período (LOSADA, 2009). Se durante a vigência dos Impérios Ibéricos o termo cidadão estava intimamente ligado a seu par, vizinho, e indicava o pertencimento a uma cidade ou uma vila, durante o processo emancipatório passou a designar o termo cidadão a uma comunidade imaginada, nos termos de Benedict Anderson (2008). Antes, indicava um indivíduo com certos privilégios e obrigações no mundo local, para depois

\footnotetext{
${ }^{12}$ No caso brasileiro do século XIX, WERNECK VIANNA, 1997, apontou a singularidade do Estado como administrador metafísico do tempo e a formação de uma teoria política que se submete aos fatos, aportando assim em uma dialética que se expressa em "tranquila teoria". Quanto aos intelectuais, o mesmo WERNECK VIANNA, 2001, é taxativo sobre a separação entre o pensar e o agir.
} 
se ampliar a uma esfera mais ampla, conquanto o novo centro fosse ampliando e garantindo soberania sobre território.

Em geral, as disputas por soberania dos novos centros políticos, incluindo a experimentação de Bolívar, a fragmentação da América Central, e a incursão brasileira às margens do Prata, lograram diversos movimentos sociais e políticos, arrastaram regiões e suas populações ao seu movimento centrípeto e passaram lentamente a se definirem enquanto Estado-Nação. Libertados do jugo imperial, estabeleceriam a criatividade para dar plástica às instituições, e conceberiam uma nova experiência e uma nova sensibilidade temporal. Seguindo este raciocínio, uma nova concepção de história e experimentação do tempo se constituiu nas primeiras décadas do século XIX, originários da desarticulação dos Impérios Ibéricos. Assim, foram as mudanças políticas que sustentaram a transformação semântica da história, sem que existisse uma elaboração intelectual prévia (PADILLA, 2009: 571).

Excetuando-se o caso do Haiti, modularmente representado pela violência revolucionária e sua extremada aceleração temporal, a região passaria a gestar um novo espaço de experiência com relação ao tempo histórico, em termos de uma linguagem que associaria a contemporaneidade e a filosofia da história. O conceito de história, deixaria de expressar-se através da concepção circular e pedagógica da historia magister vitae para a concepção moderna de história, cindindo, em linguagem koseleckeana, o espaço de experiência do horizonte de expectativa. Redesenhando as modalidades políticas e se insurgindo contra as antigas valorações de pertencimento, o presente se abriria em sua diversidade de opções. Essa abertura se fecharia no momento em que cada região começou a fabricar seu próprio espelho a partir do passado que se separavam e negavam. Desta maneira, a flecha direcionada ao futuro, teria que colocar seu arco no passado.

Se até meados do século XIX, essa primeira geração de polígrafos ensaístas se voltou para as instituições e para o território, foram nas últimas décadas do século XIX que os aspectos conceituais da sociologia adquiriram notoriedade. Uma geração de ensaístas, como Rodó, Martí, Eugenio Maria de Hostos, Sílvio Romero e Euclides da Cunha, assinalariam a importância de uma reflexão centrada nas sociedades deste território. No fim do século XIX e início do XX, a ação desta geração de polígrafos passou a se destacar tendo como uma de suas principais preocupações a busca pela definição de uma ontologia social que diferenciava o tempo-espaço do continente em relação a outras regiões do Ocidente. A partir dos diagnósticos, diferentes entre si, se 
observaria como substrato comum, a perspectiva de uma separação nítida entre o Estado e a sociedade civil. Esse diagnóstico da fratura entre a sociedade e a política, no tempoespaço da região, se tornaria o argumento central para a busca de soluções e empreendimentos originais e criativos. Surgiria nessa geração, um profundo desconforto na aplicabilidade de modelos e respostas exógenas aos diagnósticos efetuados.

Para estes escritores, o ensaio funcionou como essa forma própria de expressão nas reflexões em torno de uma identidade ibero-americana, a qual pode se entender como a busca por uma americanidade, que definiria em forma e conteúdo grande parte da tradição ensaística continental. A proliferação do ensaio na América Latina ajudou a configurar um pensamento que tendeu a expressar-se através de uma relação com sua sociedade e sua natureza, adquirindo uma função de impacto no mundo público, impacto que consistiria em sugerir, meditar, estimular e construir determinada realidade. (GOMES-MARTINEZ, 1992; RAMOS, 2008) A partir de sua posição e de sua experiência intelectual, os pensadores latino-americanos tiveram que desenvolver estratégias e aceitar o axioma excludente da modernidade central do sistema-mundo, afirmação e negação, ser o mesmo e o outro, contudo sabotaram-na com as técnicas do ensaio: uma maneira de raciocinar e de pensar que exporia as ideias em forma de opiniões pessoais e provisórias.

Um bom exemplo dessa característica peculiar da tradição latino-americana seria que a construção do Estado e a ideia de nação no subcontinente não poderiam se pautar pelos desejos de homogeneidade cultural. A heterogeneidade deveria ser expressa através de um tipo de texto que fosse capaz de capturar a adversidade de um território híbrido. A construção de imagens, através das interpretações realizadas e possibilitadas pela forma escolhida de apresentação das ideias, deveria constituir-se sob um suporte de escrita que fosse possível captar a originalidade do tempo-espaço nos quais estavam inseridos. A abertura e flexibilidade do ensaio se associariam à própria plasticidade do conteúdo tratado.

A partir das características do ensaio como forma, e seu dinamismo na escrita, fora possível capturar o movimento de construir-se pela proposição de algo novo, de uma nova experiência da modernidade que apesar dos seus contratempos, se realizava fora do contexto europeu. ${ }^{13} \mathrm{O}$ conteúdo criativo e inerente deste movimento de

\footnotetext{
${ }^{13}$ Como observou Houvenaghel existe uma tendência geral em analisar o ensaio americano a partir do conteúdo, esquecendo-se da forma. "A crítica tende, claramente, a inclinar-se em favor dos conteúdos ideológicos do ensaio, em detrimento dos valores expressivos do mesmo, e por geral, recusam ademais,
} 
construção não poderia ser mediado pelas formas convencionais operadas em outros locais. A hipótese que se levanta é que esta experiência, que se relaciona à posição do ensaísta enquanto local em que se expressa, é transposta ao texto. ${ }^{14}$

Esse ponto se relaciona a três questões. A primeira diz respeito à persistência de práticas cognitivas do mundo em territórios fora do eixo europeu e sua imbricação com a forma como as ideias são apresentadas. A segunda aponta para uma característica típica desses territórios, nos quais existiria uma confluência para a inventividade, em seu aspecto construtivo, e o inacabamento, se comparado, como fazem os ensaístas, a outros andamentos modernos. Outra hipótese que se levanta a partir dessas considerações, é a concepção desses territórios como um campo de experimentação da modernidade. Assim, a América Latina, na visão de seus intérpretes emergiria como um espaço de projetos. ${ }^{15}$ Não obstante, apresentariam como fundamento um caráter dialógico das análises, fazendo emergir comparações com outras experiências, como a inglesa, a norte-americana e a francesa. Emergindo com maior clareza as diferenças no andamento moderno, as singularidades do próprio território e sua natureza e a pluralidade de sua constituição social.

Desta experiência do confronto insurgia diferentes tempos históricos que coexistiam e conferiam especial densidade à realidade que interpretaram, em um esforço de compor o mapa da cultura, revelando sua capacidade de mediador entre mundos e articulador de experiências. ${ }^{16}$ A comparação seria um poderoso recurso não só ao cotejarem semelhanças e diferenças que se produziriam em espaços geográficos e sociais distintos, mas também entre as culturas presentes nesse espaço. Em outras palavras, os contrastes internos presentes na sociedade informariam também os contrastes em relação ao resto do mundo, esboçando uma peculiar cartografia semântica a partir dessas relações entre tempo e -espaço distintos.

No fundo, a argumentação proposta ao ensaio perpassaria a consideração de entendê-lo como uma forma, dentre outras, de teorização produzida nas margens do Ocidente brotado pela colonização europeia, e não apenas como a expressão exógena que invadiria uma tradição nacional ou regional. Explicitando o engajamento pela

vincular os aspectos formais do texto ensaístico com sua mensagem ideológica" (HOUVENAGHEL, 2002: 13).

${ }^{14}$ Sobre este ponto inspiro-me em MAIA, 2009 e MIGNOLO, 2013. Associado a essa perspectiva incluo a noção de posição e local de enunciação, como proposto por MAINGUENEAU, 1995.

${ }^{15}$ Sobre esta concepção de projetos, que incluem em suas formulações o dualismo entre inventividade e pragmatismo, inspiro-me sobretudo em BARBOZA FILHO, 2000 e WERNECK VIANNA, 1997.

${ }^{16}$ WEINBERG, 2002. 
posição geográfica na configuração do mundo ocidental. Traria em seu bojo a presença constante do outro, que produziria a estranheza da falta ou do excesso, e que muitas vezes faria transbordar nas narrativas o sentimento de desterro, traço comum a diversos intelectuais latino-americanos.

Outro aspecto fundamental do ensaio latino-americano seria a temporalidade que o encerra. O seu caráter imediato revelaria a ânsia intelectual pela construção de uma modernidade americana. Essa temporalidade imediata do ensaio e sua relação direta com o pragmatismo e a inventividade oriundos da necessidade imposta pela tábula rasa em que fora posta a situação americana e periférica do século XIX. Em um primeiro momento, imperiosa necessidade de construção de seu Estado, e depois, de uma interpretação de seu território e sua população. Um movimento que oscilaria de uma proposição individual, efetuado através do ensaio, a uma concepção de palavra pública, ${ }^{17}$ e sua entrada no universo de publicidade das ideias.

\section{Palavras Finais}

Durante o século XX, o ensaísmo latino-americano cresceu em autores, temas e formulações diversas sobre o progresso, a história, a política, a sociologia e a crítica da cultura latino-americana, a cidade, a desterritorialização, a função do escritor na sociedade, a crítica literária frente à poética europeia. Com o passar do tempo, o ensaio adquiriu novas feições e se abriu cada vez mais.

Um simples olhar sobre a produção ensaística do século XX pode apontar sua vasta diversidade de temas e estilos, formas e sentidos que põe em relevo um significativo leque destas identidades múltiplas do ensaio. Octavio Paz, com seu perfil filosófico poético, se abeirou de sua cultura através da psicologia da mexicanidade que se traduziu no "labirinto da solidão", enquanto os "sete ensaios" de Mariátegui, de forte viés marxista, recuperariam o comunismo incaico ancestral como modelo de uma sociedade mais justa a ser construída. E os ensaios de conjuntura do marxismo acadêmico, como os de Ruy Mauro Marini, a desvelar o processo de espólio, subdesenvolvimento e dependência do continente latino-americano.

\footnotetext{
${ }^{17}$ Aproprio-me livremente desta concepção de palavra pública a partir de LECLERC, 2004 e POCOCK, 2003.
} 
O pessimismo de Martinez Estrada que refletiu sobre a psique social dos grupos rurais e urbanos da Argentina, enquanto o espirituoso Fernando Ortiz definiu a cultura cubana a partir do contraponto entre o açúcar e o tabaco, dois elementos importantes na cultura cubana, base de seu desenvolvimento econômico e cultural, que ajudariam a definir as questões antropológicas da identidade cubana, construída a partir dos processos de transculturação.

José de Vasconcelos acreditou na possibilidade, ainda que utópica, de uma nova raça cósmica que surgiria dos processos de mestiçagem do subcontinente. Carlos Fuentes concentrou na metáfora do espelho enterrada a complexidade de um continente que foi resultado da exploração colonial e ao mesmo tempo herdeira de tradições transplantadas. Alfonso Reyes, com habitual erudição e estilo, concebeu imagens, muitas vezes utópicas sobre a inteligência americana, enquanto Ángel Rama, em sua reflexão, remontou à vida cultural das cidades coloniais como células originais da cultura letrada nas Américas. Cidades letradas que são elas próprias espaços privilegiados de uma nova cultura que produziu uma literatura transcultural.

Nessa literatura de autoexame e de diagnóstico, que começou muito cedo no discurso latino-americano, a busca conduziu à indagação sobre o passado. A emergência da preocupação sociológica, que em um lento processo subsume a teoria política, condensou no ensaísmo social as interpretações sobre o continente. De todo modo, o ensaio enquanto forma de escrita se associou ao conteúdo e ao contexto em que foi produzido e sua análise deve levar em consideração a constituição de uma episteme periférica e a experiência intelectual latino-americana.

\section{Referências bibliográficas}

ADORNO, Theodor (2003). Notas de Literatura I. São Paulo: Editora 34.

ANDERSON, Benedict (2008). Comunidades Imaginadas. São Paulo: Companhia das Letras.

ARCINIEGAS, Germán (1983). Nuestra América es un ensayo. In: LARROYO, Francisco et al. Filosofía de la historia latinoamericana. Bogotá: El Búho.

BARBOSA FILHO, Rubem (2000). Tradição e Artifício: Iberismo e Barroco na Formação Americana. Belo Horizonte: Editora UFMG.

CARVALHO, José Murilo de (1980). A construção da ordem: a elite política imperial. Rio de Janeiro: Campus.

EARLE, Peter G (1982). El ensayo hispanoamericano, del modernismo a la modernidad. Revista Iberoamericana, ${ }^{\circ}{ }^{\mathrm{s}} 118-119$ p.46-57. 
FERES JÚNIOR, João (2009). El concepto de América en el mundo atlántico (17501850): Perspecti- vas teóricas y reflexiones sustantivas a partir de una comparación de múltiples casos. In: LOSADA, Cristobal. SEBASTIAN, Javier. Diccionario político y social del mundo iberoamericano La era de las revoluciones, 1750-1850. Madrid: Fundación Carolina Sociedad Estatal de Conmemoraciones Culturales y Centro de Estudios Políticos y Constitucionales de Madrid.

FERREIRA, Fatima (2009). Entre viejos y nuevos sentidos: «Pueblo» y «pueblos» en el mundo ibe- roamericano, 1750-1850. In: LOSADA, Cristobal. SEBASTIAN, Javier. Diccionario político y social del mundo iberoamericano La era de las revoluciones, 1750-1850. Madrid: Fundación Carolina Sociedad Estatal de Conmemoraciones Culturales y Centro de Estudios Políticos y Constitucionales de Madrid.

GOLDMAN, Noemi (2009). Legitimidad y deliberación. El concepto de opinión pública en Ibero- américa, 1750-1850. In: LOSADA, Cristobal. SEBASTIAN, Javier. Diccionario político y social del mundo iberoamericano La era de las revoluciones, 1750-1850. Madrid: Fundación Carolina Sociedad Estatal de Conmemoraciones Culturales y Centro de Estudios Políticos y Constitucionales de Madrid.

GÓMES-MARTÍNEZ, José Luis (1992). Teoría del Ensayo. México, UNAM.

GREENBLATT, S (1996). Possessões maravilhosas: o deslumbramento do Novo Mundo. São Paulo: EDUSP.

HAMILTON, Carlos (1972). El Ensayo Hispanoamericano. Madrid, Ediciones Iberoamericanas.

HARO, Pedro Haullón de (1992). Teoría del Ensayo. Madrid, Verbum.

HELLER, Agnes (1982). O Homem do Renascimento. Lisboa: Presença.

HOUVENAGHEL, Eugenia (2002). Reivindicacion de una vocacion americanista: Alfonso Reyes - América como obra educativa. Genebra, Livraria Droz

KOSELLECK, Reinhart (2006). Futuro Passado: Contribuição à semântica dos tempos históricos. Rio de Janeiro: Contraponto/Puc-Rio

LECLERC, Gérard (2004). Sociologia dos Intelectuais. São Leopoldo, Editora Unisinos.

LIMA, Luiz Costa (1995). Vida e Mimeses. São Paulo: Editora 34. . (1993) Limites da Voz: Montaigne, Schlegel. Rio de Janeiro: Rocco.

LOMMÉ, Georges (2009). De la República y otras repúblicas: La regeneración de un concepto. In: LOSADA, Cristobal. SEBASTIAN, Javier. Diccionario político y social del mundo iberoamericano La era de las revoluciones, 1750-1850. Madrid: Fundación Carolina Sociedad Estatal de Conmemoraciones Culturales y Centro de Estudios Políticos y Constitucionales de Madrid.

LOSADA, Cristobal (2009). Ciudadano y vecino en Iberoamérica, 1750-1850: Monarquía o República. In:__... SEBASTIAN, Javier. Diccionario político y social del mundo iberoamericano La era de las revoluciones, 1750-1850. Madrid: Fundación Carolina Sociedad Estatal de Conmemoraciones Culturales y Centro de Estudios Políticos y Constitucionales de Madrid.

LOVELUCK, Juan (1976). El ensayo hispanoamericano y su naturaleza. Los Ensayistas. I (1), 7-13.

LUKÁCS, Georg (2009). A Teoria do Romance: um ensaio histórico-filosófico sobre as formas da grande época. São Paulo: Editora 34.

(1985) Sobre la esencia y forma del ensayo (Carta a Leo Popper). In: El alma y las formas y Teoría de la novela, Barcelona, Grijalbo, 15-39. 
MAIA, João Marcelo (2008). A terra como invenção: o espaço no pensamento social brasileiro. Rio de Janeiro: Zahar.

(2009) Pensamento brasileiro e teoria social: notas para uma agenda de pesquisa. Revista Brasileira de Ciências Sociais. São Paulo: v. 24, n. 71, Outubro. pp.155168, 2009.

. (2011) Ao Sul da Teoria: a atualidade teórica do pensamento social brasileiro. Revista Sociedade e Estado, volume 26, números 2 Maio/Agosto. pp. 71-94, 2011.

MAÍZ, Claudio (2003). Problemas genológicos del discurso ensayístico: origen y configuración de un género. Acta Literaria, n $^{\circ} 28$ (79-105), 2003. Edição Digital disponível em: http://www.scielo.cl/pdf/aclit/n28/art07.pdf

MIGNOLO, Walter (2013). Histórias locais/Projetos globais. Colonialidade, saberes subalternos e pensamento liminar. Belo Horizonte: Ed. UFMG.

MONTAIGNE, Michel de (2000). Ensaios. São Paulo: Martins Fontes.

MONTIEL, Edgar (2000). El ensayo americano, centauro de los géneros. In: . $E l$ humanismo americano. Filosofía de una comunidad de naciones. Perú: Fondo de Cultura Económica, pp. 169-177.

NOYAMA, Samon (2009). Adorno e o 'ensaio como forma'. Revista Ítaca. Ouro Preto, UFOP, n14, pp. 135-147, 2009.

OBALDIA, Claire de (1995). The Essayistic Spirit: literature, modern criticism and the essay. Clarendon: Oxford University Press.

ORJUELA, Héctor (2002). Primicias del ensayo em Colombia: el discurso ensaystico colonial. Bogotá, Editora Guadalupe.

OVIEDO, José Miguel (1992). Breve História del Ensayo Hispanoamericano. Madrid, Alianza.

PADILLA, Guillermo (2009). Historia, experiencia y modernidad en Iberoamérica, 1750-1850. In: LOSADA, Cristobal. SEBASTIAN, Javier. Diccionario político y social del mundo iberoamericano La era de las revoluciones, 1750-1850. Madrid: Fundación Carolina Sociedad Estatal de Conmemoraciones Culturales y Centro de Estudios Políticos y Constitucionales de Madrid.

PINTO, Manuel da Costa (1998). Albert Camus: um elogio do ensaio. São Paulo: Ateliê Editorial.

POCOCK, J. G. A (2003). Linguagens do Ideário Político. São Paulo: Edusp.

PRATT, Mary Louise (1999). Os olhos do Império: relatos de viagem e transculturação. Bauru: Edusc.

RAMA, Angél (2001). Literatura e Cultura na América Latina. (Aguiar, Flávio; Vasconcelos, Sandra - orgs) São Paulo: Edusp. . (1985). A cidade das Letras. São Paulo: Brasiliense.

RAMOS, Julio (2008). Desencontros da Modernidade na América Latina: literatura e política no século XIX. Belo Horizonte: Editora UFMG.

ROLAND, Ana Maria (1997). Fronteiras da Palavra, Fronteiras da História. Brasília, Editora da Unb.

VALDES, José (2009). Ex unum, pluribus: revoluciones constitucionales y disgregación de las monarquías ibero-americanas. In: LOSADA, Cristobal. SEBASTIAN, Javier. Diccionario político y social del mundo iberoamericano La era de las revoluciones, 1750-1850. Madrid: Fundación Carolina Sociedad Estatal de Conmemoraciones Culturales y Centro de Estudios Políticos y Constitucionales de Madrid.

WASSERMAN, Fabio (2009). El concepto de nación y las transformaciones del orden político en Iberoamérica (1750-1850). In: LOSADA, Cristobal. SEBASTIAN, 
Javier. Diccionario político y social del mundo iberoamericano La era de las revoluciones, 1750-1850. Madrid: Fundación Carolina Sociedad Estatal de Conmemoraciones Culturales y Centro de Estudios Políticos y Constitucionales de Madrid.

WEINBERG, Liliana (2001). El ensayo, entre el paraíso y el infierno. México, UNAM/Fondo de Cultura Económica. (2006) Pensar el ensayo. México, Editora Siglo XXI.

WERNECK VIANNA, Luiz (1997). A Revolução Passiva: iberismo e americanismo no Brasil. Rio de Janeiro: Revan.

(2001) “O Pensar e o Agir”. Lua Nova. Revista de Cultura e Política. São Paulo: $\mathrm{N}^{\circ}$ 54. CEDEC, 2001.

ZEA, Leopoldo (org.). (1995) Fuentes de la Cultura Latinoamericana. México, F.C.E., 2 vols. . (1972) America como conciencia. México, Unam.

Artigo recebido em 02 de outubro de 2019

Aprovado em 08 de maio de 2020

DOI: $10.12957 /$ intellectus.2020.45728 